\title{
PENGARUH MODEL PEMBELAJARAN KOOPERATIF BERBASIS HOTS TERHADAP KEMAMPUAN BERPIKIR MATEMATIS
}

\author{
Rostien Puput Anggoro \\ Program Studi Pendidikan Matematika FKIP UAD \\ Jl. Ringroad Selatan, Tamanan, Banguntapan, Bantul \\ rostien.anggoro@pmat.uad.ac.id
}

\begin{abstract}
ABSTRAK
Penelitian ini bertujuan untuk : (1) mengetahui apakah model pembelajaran kooperatif tipe Jigsaw dan STAD berbasis HOTS berpengaruh terhadap kemampuan berpikir kreatif matematis, (2) membandingkan pengaruh model pembelajaran kooperatif tipe Jigsaw dan STAD berbasis HOTS terhadap kemampuan berpikir kreatif matematis. Desain penelitian yang digunakan adalah penelitian eksperimen semu dengan pretest posttest non-equivalent group design. Penelitian ini dilakukan di SMK Boedi Oetomo 3 Maos pada bulan April 2019 semester II pada tahun akademik 2018/2019. Populasi dalam penelitian ini adalah semua siswa kelas XI Teknik Kendaraan Ringan (TKR) di SMK Boedi Oetomo 3 Maos yang terdiri dari empat kelas. Teknik pengambilan sampel dilakukan dengan teknik random sampling sehingga dipilih dua kelas, kelas XI TKR 1 sebagai kelas eksperimen I dengan model pembelajaran kooperatif tipe Jigsaw berbasis HOTS dan kelas XI TKR 2 sebagai kelas eksperimen II dengan model pembelajaran kooperatif tipe STAD berbasis HOTS. Instrumen penelitian yang digunakan adalah tes kemampuan berpikir kreatif matematis. Uji hipotesis pada penelitian ini menggunakan uji t. Hasil penelitian menunjukkan bahwa: (1) Model pembelajaran kooperatif tipe Jigsaw dan STAD berbasis HOTS berpengaruh terhadap kemampuan berpikir kreatif matematis, (2) terdapat perbedaan pengaruh antara pembelajaran kooperatif model tipe Jigsaw dan STAD berbasis HOTS terhadap kemampuan berpikir kreatif matematis, dan 3) model pembelajaran kooperatif tipe Jigsaw berbasis HOTS lebih berpengaruh daripada tipe STAD berbasis HOTS terhadap kemampuan berpikir kreatif matematis.
\end{abstract}

Kata Kunci: Pembelajaran Kooperatif, Jigsaw, STAD, HOTS, Kemampuan Berpikir Kreatif Matematis.

\begin{abstract}
This research was aimed to: (1) determine whether the Jigsaw and STAD type cooperative learning models based on HOTS affect the mathematical creative thinking ability, (2) compare the effect of the Jigsaw and STAD type cooperative learning models on HOTS based on mathematical creative thinking abilities. The research design used was quasi-experimental research with a pretest posttest non-equivalent group design. This research was conducted at the Boedi Oetomo 3 Maos Vocational School on April 2019 semester II in the academic year of 2018/2019. The population in this research were all students of class XI Light Vehicle Engineering in Boedi Oetomo 3 Maos Vocational School which consisted of four classes. The sampling technique was done by random sampling technique so that two classes were selected, class XI Light Vehicle Engineering 1 as an experimental class I with a Jigsaw type cooperative learning model based on HOTS and class XI Light Vehicle Engineering 2 as an experimental class II with a type of STAD cooperative learning model based on HOTS. The research instrument used was a test of mathematical creative thinking ability. Hypothesis testing in this study uses the t test. The results showed that: (1) cooperative learning model type Jigsaw and STAD based on HOTS was affect on mathematical creative thinking ability, (2) there was a difference in effect between cooperative learning model type Jigsaw and STAD based HOTS on mathematical creative thinking ability, and 3) cooperative
\end{abstract}


learning model type Jigsaw based on HOTS is more affect than the STAD type based on HOTS for mathematical creative thinking ability.

Keywords: Cooperative learning, Jigsaw, STAD, HOTS, mathematical creative thinking ability.

\section{Pendahuluan}

Matematika merupakan ilmu pengetahuan yang sangat penting bagi manusia dalam menjalani hidup dan kehidupan. Sehingga matematika menjadi mata pelajaran yang wajib diajarkan di seluruh jenjang, yaitu dari jenjang sekolah dasar, menengah sampai perguruan tinggi. Suherman (2003) menjelaskan bahwa tujuan umum diberikannya matematika pada jenjang sekolah dasar dan menengah adalah mempersiapkan agar siswa sanggup menghadapi perubahan keadaan di dalam kehidupan dan di dunia yang selalu berkembang melalui latihan bertindak atas dasar pemikiran secara logis, rasional, kritis, cermat, jujur, efektif, dan efisien; dan mempersiapkan siswa agar dapat menggunakan matematika dan pola pikir matematika dalam kehidupan sehari-hari serta dalam mempelajari berbagai ilmu pengetahuan.

Tujuan matematika diajarkan kepada siswa adalah untuk membantu melatih pola pikir siswa agar dapat memecahkan masalah secara kreatif dan mandiri. Gagne (Uno, 2007: 134) mengatakan bahwa "keterampilan berpikir kreatif (creative thinking), yakni keterampilan seseorang dalam menggunakan proses berpikirnya untuk menghasilkan ide baru, kontruktif, dan baik berdasarkan konsep-konsep, prinsipprinsip yang rasional, maupun persepsi dan intuisi”. Kreatif sangat diperlukan siswa untuk mengaktualisasikan dirinya, menemukan berbagai alternatif dalam pemecahan masalah, meningkatkan kualitas hidup, dan meningkatkan inovasi dan melakukan perubahan dalam hidupnya. Prasetyo dan Suhendri (2016: 451) mengatakan bahwa "kemampuan berpikir kreatif matematis merupakan kemampuan peserta didik dalam memahami dan menyelesaikan masalah dalam matematika dengan strategi dan cara yang bervariasi”. Kemampuan berpikir kreatif matematis antara individu yang satu dengan yang lain berbeda-beda. Sedangkan menurut Suwarti dalam Sari (2016: 94) mengatakan bahwa "kemampuan berpikir kreatif matematis adalah kemampuan siswa dalam memahami dan menyelesaikan suatu masalah dalam matematika dengan strategi serta cara yang bervariasi (divergen) sehingga proses berpikir kreatifnya dapat digunakan untuk proses 
pemecahan masalah matematika siswa secara langsung dengan tepat dan cepat".

Chatib dalam Noma (2016: 63), mengatakan bahwa kemampuan berpikir tingkat tinggi dapat membantu siswa untuk mencapai hasil yang berkualitas serta untuk memahami suatu informasi. Agung, J (2018: 2) berpendapat, High Order Thinking Skills (HOTS) adalah proses berpikir yang mengharuskan siswa untuk memperluas pola pikir dengan memanipulasi ide-ide yang memberikan siswa solusi untuk tantangan atau kasus baru. Sedangkan Krathwohl dalam Suwarsi (2018: 250) mengatakan bahwa ranah berpikir Bloom mengkategorikan indikator untuk mengukur keterampilan berpikir tinggi meliputi menganalisis, mengevaluasi dan mencipta/mengkresasi.

Melalui proses kegiatan pembelajaran, siswa dapat dilatih untuk meningkatkan kemampuan berpikir tingkat tinggi khususnya dalam pembelajaran matematika. Kemampuan matematis diantaranya kemampuan berpikir kreatif dapat ditumbuhkan melalui kegiatan pembelajaran matematika (Suherman, 2003). Pembelajaran matematika diharapkan menjadi suatu kegiatan yang menyenangkan bagi siswa. Sehingga materi matematika yang diajarkan dapat diterima siswa dengan mudah dan siswa dapat lebih mengeksplor dalam mempelajarinya sesuai dengan kemampuan pemahamannya.

Berdasarkan hasil observasi pembelajaran di kelas XI SMK Boedi Oetomo 3 Maos, Cilacap, pada bulan September 2018, diketahui bahwa kemampuan berfikir kreatif siswa masih rendah. Terlihat saat pembelajaran di dalam kelas, siswa belum bisa dan tidak terbiasa mengerjakan soal secara mandiri, siswa masih bergantung kepada guru. Siswa juga kurang dilatih mengerjakan soal yang berkaitan dengan pemecahan masalah. Selain itu, model pembelajaranyang digunakan guru bersifat konvensional. Guru hanya memberikan materi di depan kelas dan siswa mencatatnya dibuku tanpa memahaminya. Pembelajaran lebih terpusat pada guru dan siswa kurang dilibatkan dalam menyelesaikan soal yang diberikan. Guru kurang memberi kesempatan kepada siswa untuk menyelesaikan soal di depan kelas dan guru juga kurang menggali kreatifitas siswa dalam menyelesaikan soal, karena soal yang diberikan hanya memiliki jawaban benar yang tunggal. Keadaan ini mengakibatkan siswa kurang berfikir kreatif dan berkonsentrasi dalam menyelesaikan soal-soal matematika yang membutuhkan banyak strategi. Jadi, jika siswa mengerjakan tugas yang diberikan oleh guru, mereka 
menyelesaikan tugas tersebut hanya menggunakan cara dan langkah-langkah yang diajarkan oleh guru mereka.

Melihat permasalahan tersebut, maka untuk mengatasinya diperlukan inovasi model pembelajaran yang mampu melibatkan siswa aktif dalam proses pembelajaran. Salah satu model pembelajaran yang dapat digunakan untuk mengukur kamampuan siswa serta dapat melibatkan siswa secara aktif yaitu model pembelajaran kooperatif. Model pembelajaran ini menghimpun siswa dalam suatu kelompok yang terdiri dari beberapa orang untuk berinteraksi satu sama lain untuk menyampaikan pendapat masing-masing. Jenis model pembelajaran kooperatif yang dipilih adalah model pembelajaran kooperatif tipe Jigsaw dan Student Teams Achievement Division (STAD). Menurut Aronson dalam Untari (2013: 4) pembelajaran kooperatif tipe Jigsaw merupakan jenis model pembelajaran kooperatif yang mendorong siswa untuk lebih aktif. Faturrohman (2016: 63) berpendapat, model pembelajaran kooperatif tipe Jigsaw adalah model pembelajaran kooperatif dengan kelompok siswa yang terdiri dari 4-6 siswa heterogen dengan berbagai subbahan, berkolaborasi dan memiliki tanggung jawab masing-masing untuk membahas materi tersebut dengan anggota kelompok lainnya (kelompok asal). Anggota kelompok yang berbeda dengan topik yang sama bertemu untuk diskusi (kelompok ahli). Kemudian anggota kelompok ahli kembali ke kelompok asal untuk menjelaskan kepada anggota kelompok materi yang telah dipelajari. Sedangkan menurut Prabowo dan Sunaryo (2015: 3), STAD merupakan model pembelajaran kooperatif yang mudah diterapkan dalam pembelajaran karena kesederhanaan langkahlangkahnya. Kedua model pembelajaran kooperatif (Jigsaw dan STAD) diberikan masalah yang berorientasi pada keterampilan berpikir tingkat tinggi (HOTS).

Menurut Agung, J (2018: 2) Keterampilan Berpikir Tingkat Tinggi (HOTS) adalah proses berpikir yang mengharuskan siswa untuk memperluas pola pikir mereka dengan memanipulasi ide-ide yang memberi siswa solusi untuk tantangan atau kasus baru. Sedangkan menurut beberapa ahli dalam Jailani (2016: 112), pembelajaran HOTS adalah: 1) Liu dan Fisher, HOTS merupakan pemikiran yang melibatkan analisis, sintesis dan evaluasi. 2) Krulik dan Rudnick, HOTS merupakan berpikir kritis dan kreatif. 3) Anderson dan Krathwohl, HOTS mencakup proses analisis, sintesis, dan kreasi. 
Rumusan masalah dari penelitian ini adalah : 1) Apakah model pembelajaran kooperatif tipe Jigsaw dan STAD berbasis HOTS berpengaruh terhadap kemampuan berpikir kreatif matematis? 2) Apakah terdapat perbedaan pengaruh model pembelajaran kooperatif tipe Jigsaw dan STAD berbasis HOTS terhadap kemampuan berpikir kreatif matematis?

Tujuan dari penelitian ini adalah untuk: 1) mengetahui apakah model pembelajaran kooperatif tipe Jigsaw dan STAD berbasis HOTS berpengaruh terhadap kemampuan berpikir kreatif matematis, (2) membandingkan pengaruh model pembelajaran kooperatif tipe Jigsaw dan STAD berbasis HOTS terhadap kemampuan berpikir kreatif matematis.

\section{Metode Penelitian}

Jenis penelitian ini adalah penelitian kuantitatif dengan menggunakan metode eksperimen semu (quasi-experimental) yang bertujuan untuk membandingkan dua kelompok eksperimen. Desain penelitian ini dipilih karena para peneliti tidak melakukan tugas acak, melainkan menggunakan kelompok yang ada sebagai kelompok eksperimen. Penelitian ini dilakukan di SMK Boedi Oetomo 3 Maos yang berlokasi di Jalan Raya Penisihan No.
300 Penisihan Maos, Cilacap, Jawa Tengah. Pelaksanaan penelitian ini meliputi proses pembelajaran dan pengumpulan data yang dilakukan pada tanggal 15-26 April 2019 semester II pada tahun akademik 2018/2019 dengan total 60 siswa. Populasi dalam penelitian ini adalah semua siswa kelas XI Teknik Kendaraan Ringan (TKR) semester II SMK Oetomo 3 Maos yang terdiri dari empat kelas. Teknik pengambilan sampel dilakukan dengan teknik random sampling sehingga dipilih dua kelas, kelas XI TKR 1 sebagai kelas eksperimen I dan kelas XI TKR 2 sebagai kelas eksperimen II.

Dalam penelitian ini teknik yang digunakan untuk pengumpulan data adalah teknik tes. Tes dalam penelitian ini adalah soal pretest dan posttest untuk mengukur kemampuan berpikir kreatif matematis siswa. Tes ini berupa soal uraian yang terdiri dari 5 pertanyaan. Teknik analisis data yang digunakan adalah: 1) Analisis Deskriptif, data yang dideskripsikan adalah data yang diperoleh dari pengukuran pada variabel penelitian (variabel dependen), yaitu kemampuan berpikir kreatif matematis. Data yang telah diperoleh dihitung nilai rata-rata dan kemudian diinterpretasikan ke dalam kriteria yang telah ditentukan dan persentasenya ditentukan. 2). Analisis Statistik Inferensial, yaitu 
dengan statistik uji-t. Analisis ini dilakukan untuk mengetahui pengaruh pembelajaran kooperatif tipe Jigsaw dan STAD berbasis HOTS terhadap kemampuan berpikir kreatif matematis.

\section{Hasil dan Pembahasan}

Dari hasil perhitungan, diperoleh angka-angka statistik hasil pretest dan posttest kemampuan berpikir kreatif matematis siswa secara deskriptif yang dinyatakan dalam tabel 1 berikut.

Tabel 1. Hasil Pretest dan Posttest

\begin{tabular}{|c|c|c|c|c|}
\hline \multirow[t]{2}{*}{ Nilai } & \multicolumn{2}{|c|}{$\begin{array}{c}\text { Kelas XI } \\
\text { TKR } 1\end{array}$} & \multicolumn{2}{|c|}{$\begin{array}{c}\text { Kelas XI } \\
\text { TKR } 2\end{array}$} \\
\hline & Pretest & Posttest & Pretest & Posttest \\
\hline Min & 45 & 62 & 43 & 60 \\
\hline Maks & 70 & 80 & 70 & 76 \\
\hline Rerata & 60,4 & 73,2 & 59,8 & 68,4 \\
\hline
\end{tabular}

Dari Tabel 1. menunjukkan bahwa untuk nilai rata-rata pretest kemampuan berpikir kreatif matematis siswa pada kelompok eksperimen pertama kelas XI TKR 1 yang menerapkan model pembelajaran tipe Jigsaw berbasis HOTS memperoleh nilai 60,4 dan hasil nilai rata-rata posttest kemampuan berpikir kreatif matematis siswa meningkat menjadi 73,2. Sehingga dapat dikatakan penerapan model pembelajaran tipe Jigsaw berbasis HOTS berpengaruh terhadap kemampuan berpikir kreatif matematis siswa. Hal ini didukung oleh penelitian Zakaria, dkk. (2013 bahwa pembelajaran kooperatif terutama tipe
Jigsaw dapat meningkatkan hasil belajar matematika dan kepercayaan diri siswa.

Sedangkan untuk nilai rata-rata pretest kemampuan berpikir kreatif matematis siswa kelompok eksperimen II kelas XI TKR 2 yang menerapkan model pembelajaran tipe STAD berbasis HOTS memperoleh nilai 59,8 dan hasil nilai rata-rata posttest kemampuan berpikir kreatif matematis siswa meningkat menjadi 68,4. Sehingga dapat dikatakan penerapan model pembelajaran tipe STAD berbasis HOTS berpengaruh terhadap kemampuan berpikir kreatif matematis siswa.

Didukung oleh penelitian Novianti (2013) bahwa model pembelajaran kooperatif tipe Student Team Achievement Division (STAD) dalam pembelajaran matematika dapat meningkatkan prestasi belajar matematika siswa dibandingkan dengan model pembelajaran konvensional pada motivasi tinggi, sedang atau rendah.

Uji normalitas dilakukan untuk mengetahui apakah data dari tiap eksperimen I (kelas XI TKR 1) dan eksperimen II (kelas XI TKR 2) berasal dari populasi berdistribusi normal atau tidak. Dalam penelitian ini menggunakan uji Chi-Kuadrat dengan taraf signifikasi 5 $\%$. Adapun hasil perhitungan normalitas dapat dilihat pada tabel 2 . 
Tabel 2. Hasil Uji Normalitas

\begin{tabular}{|c|c|c|c|c|}
\hline \multirow[t]{2}{*}{ Hasil } & \multicolumn{2}{|c|}{$\begin{array}{c}\text { Kelas XI } \\
\text { TKR } 1\end{array}$} & \multicolumn{2}{|c|}{$\begin{array}{c}\text { Kelas XI } \\
\text { TKR } 2\end{array}$} \\
\hline & Pretest & Posttest & Pretest & Posttest \\
\hline$x_{\text {hitung }}^{2}$ & 3,5247 & 0,1815 & 2,8477 & 0,8945 \\
\hline$x_{\text {tabel }}^{2}$ & 9,4877 & 7,8147 & 7,8148 & 5,9915 \\
\hline $\begin{array}{l}\text { Taraf } \\
\text { Sign }\end{array}$ & 0,05 & 0,05 & 0,05 & 0,05 \\
\hline $\mathrm{Dk}$ & 5 & 4 & 3 & 2 \\
\hline Ket & & rdist & Nor1 & \\
\hline
\end{tabular}

Uji homogenitas ini dilakukan untuk mengetahui apakah data kemampuan berpikir kreatif matematis siswa kelas eksperimen I (XI TKR 1) dan eksperimen II (XI TKR 2) homogen atau tidak. Dalam penelitian ini untuk uji homogenitas menggunakan rumus uji Barlett. Adapun hasil uji homogenitas kemampuan berpikir kreatif matematis siswa dapat dilihat pada tabel 3 berikut.

Tabel 3. Hasil Uji Homogenitas

\begin{tabular}{|c|c|c|}
\hline \multirow{2}{*}{ Hasil } & \multicolumn{2}{|c|}{ Nilai } \\
\cline { 2 - 3 } & Pretest & Posttest \\
\hline$X_{\text {hitung }}^{2}$ & 0,7615 & 3,1225 \\
\hline$X_{\text {tabel }}^{2}$ & 3,8415 & 3,8415 \\
\hline Taraf Sign & 0,05 & 0,05 \\
\hline Dk & 1 & 1 \\
\hline Keterangan & \multicolumn{2}{|c|}{ Homogen } \\
\hline
\end{tabular}

Adapun hasil uji hipotesis dua pihak kemampuan berpikir kreatif matematis siswa kelas eksperimen I dan eksperimen II dengan taraf signifikan 0,05 dan derajat kebebasan 58, diperoleh nilai kemampuan berpikir kreatif siswa $t_{\text {hitung }}=-4,624$ dan $t_{\text {tabel }}=-2,0017$. Karena $t_{\text {hitung }}>t_{\text {tabel }}$ atau $t_{\text {hitung }}<-t_{\text {tabal }}$ maka $H_{0}$ ditolak yang artinya terdapat perbedaan pengaruh penggunaan model pembelajaran kooperatif tipe Jigsaw berbasis HOTS dengan model pembelajaran kooperatif tipe STAD berbasis HOTS terhadap kemampuan berpikir kreatif siswa.

Perbedaan tersebut disebabkan oleh proses model pembelajaran kooperatif tipe Jigsaw dan STAD yang berbeda dalam setiap langkah-langkahnya. Pada penerapan model pembelajaran tipe Jigsaw siswa dibagi dalam beberapa kelompok yang terdiri dari 4-5 siswa (kelompok asal). Dalam kelompok tersebut siswa akan diberikan sub materi yang berbeda-beda, dari setiap siswa diberikan tanggungjawab untuk mempelajari materi yang telah ditentukan guru. Siswa yang diberikan sub materi akan bergabung dengan siswa yang memiliki sub materi yang sama (kelompok ahli). Setelah berdiskusi dengan kelompok ahli maka akan kembali berdiskusi dengan kelompok asal untuk saling menerangkan kepada seluruh anggota kelompok asal mengenai materi yang dipelajari dengan kelompok ahli. Sedangkan penerapan model pembelajaran kooperatif tipe STAD, siswa terlebih dahulu diberikan materi dan jelaskan oleh guru. Kemudian siswa membentuk kelompok yang terdiri dari 45 siswa dalam kemampuan yang heterogen, dalam kelompok siswa mendiskusikan materi/soal yang telah 
diberikan oleh guru. Guru meminta perwakilan dari setiap kelompok untuk mempresentasikan hasil diskusi.

Terlihat ada perbedaan dalam penerapan kedua model pembelajaran, dimana pembelajaran Jigsaw siswa terlihat lebih aktif dalam proses pembelajaran dan lebih mudah memahami materi. Hal ini sesuai dengan teori Eka Trisianawati (2016) bahwa Jigsaw memiliki beberapa kelebihan yaitu siswa lebih aktif, saling memberikan pendapat serta saling berkompetisi untuk mencapai prestasi yang baik. Siswa lebih memiliki kesempatan berinteraksi sosial dengan temannya. Siswa lebih kreatif dan memiliki tanggungjawab secara individual.

Pengaruh model pembelajaran kooperatif berbasis HOTS terhadap kemampuan berpikir kreatif siswa terlihat pada hasil nilai rata-rata kelas eksperimen I dan kelas eksperimen II setelah diberi perlakuan. Kelas eksperimen I dengan menggunakan model pembelajaran kooperatif tipe Jigsaw berbasis HOTS memperoleh nilai rata-rata sebesar 75,5. Sedangkan kelas eksperimen II dengan menggunakan model pembelajaran kooperatif tipe STAD berbasis HOTS memperoleh nilai rata-rata sebesar 70 .

Sedangkan uji hipotesis satu pihak dilakukan untuk mengetahui apakah penggunaan model pembelajaran kooperatif tipe Jigsaw berbasis HOTS lebih berpengaruh dari pada model pembelajaran tipe STAD berbasis HOTS terhadap kemampuan berpikir kreatif matematis siswa. Berdasarkan perhitungan yang telah dilakukan pada kelas eksperimen I dan kelas eksperimen II dengan taraf signifikan 0,05 dan derajat kebebasan 58, nilai kemampuan berpikir kreatif siswa $t_{\text {hitung }}=-4,67762$ dan $t_{\text {tabel }}=$ $-1,671553$. Karena $t_{\text {hitung }}<-t_{\text {tabal }}$, maka $H_{0}$ ditolak yang artinya penggunaan model pembelajaran koopertaif tipe Jigsaw berbasis HOTS lebih berpengaruh dari pada penggunaan model pembelajaran koopertaif tipe Student Teams Achievement Division (STAD) berbasis HOTS terhadap kemampuan berpikir kreatif matematis siswa. Hal ini didukung oleh penelitian Tran \& Lewis (2012) yang menyatakan bahwa pembelajaran kooperatif khususnya Jigsaw memberikan hasil positif dengan sikap siswa dalam belajar. Para siswa akan lebih memahami, dan mandiri, belajar lebih banyak dan lebih percaya diri. Dan didukung oleh hasil penelitian Juliana, M dan Surya, E (2017) bahwa pembelajaran dengan Jigsaw kooperatif efektif dengan kepercayaan diri dan hasil belajar di kelas X SMK Negeri 1 Batang Toru yang dapat dilihat dari siswa 'belajar 
kelengkapan dengan tes yang telah diberikan.

\section{Kesimpulan}

Berdasarkan hasil analisis data dan pembahasan dapat diambil kesimpulan bahwa: 1) model pembelajaran kooperatif tipe Jigsaw dan STAD berbasis HOTS berpengaruh terhadap kemampuan berpikir kreatif matematis siswa. 2) terdapat perbedaan pengaruh antara model pembelajaran kooperatif tipe Jigsaw berbasis HOTS dengan tipe STAD berbasis HOTS terhadap kemampuan berpikir kreatif matematis siswa. 3) model pembelajaran kooperatif tipe Jigsaw berbasis HOTS lebih berpengaruh dari pada tipe STAD berbasis HOTS terhadap kemampuan berpikir kreatif matematis siswa.

\section{Ucapan Terimakasih}

Peneliti mengucapkan terima kasih kepada Universitas Ahmad Dahlan melalui Lembaga Penelitian dan Pengabdian kepada Masyarakat (LPPM) yang telah memberikan dana untuk penelitian ini. Terima kasih juga disampaikan kepada Dosen dan Mahasiswa Pendidikan Matematika FKIP UAD yang telah membantu dalam proses penelitian maupun publikasi dari hasil penelitian ini.

\section{Pustaka}

Agung, J. 2018. Higher Order Thinking Skill Mahasiswa dalam Menyelesaikan Soal Struktur Aljabar Grup. Surakarta: Naskah Publikasi. Universitas Muhammadiyah Surakarta.

Fathurrohman, M. 2016. Model- Model Pembelajaran

Yogyakarta: Ar-Ruzz Media.

Jailani \& Retnawati, H. (2016). Keefektifan Pemanfaatan Perangkat Pembelajaran Berbasis Masalah untuk Meningkatkan HOTS dan Karakter Siswa.Yogyakarta. Jurnal Pendidikan dan Pembelajaran Vol. 23 No. 2 (Oktober 2016).

Juliana, M \& Surya, E. (2017). An Analysis Of Jigsaw Cooperative Effectiveness To Improve The Selfconfidence And Learning Result Of Vocational High School Students. International Journal Of Advance Research And Innovative Ideas In Education (IJARIIE). Vol. 3 , Issue 2.

Noma, L.D., Prayitno, B.A., \& Suwarno. 2016. PBL Untuk Meningkatkan Kemampuan Berpikir Tingkat Tinggi Siswa Kelas X SMA. Solo: Bioedukasi Vol. 9 No. 2. (Agustus 2016).

Novianti, I. 2013. Experimentation Cooperative Learning Student Team Achievement Division (STAD) Type Viewed From Learning Motivation. Asian Journal of Education and e-Learning. Volume 01. Issue 05. pp. 272-276.

Prabowo, A \& Sunaryo. 2015. Meningkatkan Partisipasi Aktif Mahasiswa pada Mata Kuliah Analisis Kurikulum dan Materi Pembelajaran Matematika I 
dengan Menggunakan Model Pembelajaran Kooperatif Tipe Student Teams Achievement Division (STAD). Jurnal Of Mathematics Education Alphamath. Vol 1, No.1, pp.1-11.

Prasetyo, H. \& Suhendri, H. 2016. Pengaruh metode pembelajaran brain based learning (bbl) terhadap kemampuan berpikir kreatif matematis peserta didik. Prosiding Seminar Nasional Pendidikan Matematika Unindra, Jakarta: FTMIPA Unindra.

Sari, A. D. 2016. Pengaruh penerapan model pembelajaran kooperatif tipe think pair share (TPS) terhadap kemampuan berpikiir kreatif matematika siswa. Prosiding Seminar Nasional Pendidikan Matematika, h. 91-99. Jakarta: Unindra Press.

Suherman, E, dkk. 2003. Strategi Pembelajaran Matematika Kontemporer. Bandung : JICA.

Suwarsi, Mukti, Z., \& Prabowo, A. 2018. Meningkatkan Keterampilan HOTS Siswa Melalui Permainan Kartu Soal dalam Pembelajaran PBL. Semarang: Prisma. FMIPA Universitas Negeri Semarang.

Tran, V.D \& Lewis, R. 2012. The effects of Jigsaw learning on students'attitudes in a vietnamese higher education classroom. International Journal of Higher Education. Vol. 1, No. 2.

Uno, H. 2012. Belajar Dengan Pendekatan Pembelajaran Aktif, Inovatif, Lingkungan, Kreatif, Efektif, Menarik. Jakarta: Bumi Aksara.
Untari, E. (2013). Efektifitas Model Pembelajaran Kooperatif Tipe STAD dan Jigsaw pada Prestasi Belajar Matematika Siswa SMP di Kabupaten Magetan.Jurnal Ilmiah STKIP PGRI Ngawi Vol. 11 No. 1.

Winarso, W. (2014). Membangun Kemampuan Berfikir Matematika Tingkat Tinggi Melalui Pendekatan Induktif, Deduktif dan InduktifDeduktif dalam Pembelajaran Matematika. 3(2): 97.

Zakaria, E, et al. (2013). Effect of cooperative learning on secondary school students' mathematics achievement. Scientific Research. Vol. 4, No.2, pp. 98-100. 